\title{
The Relation between the Initial Type of Schedule Used to Administer Doxorubicin and Long-Term Doxorubicin Cardiotoxicity
}

\author{
Arthur J. Weiss ${ }^{1 *}$, Irwin L. Stoloff ${ }^{1}$, Antonio C. Simoes ${ }^{2}$, Richard D. Lackman ${ }^{3}$ \\ ${ }^{1}$ Division of Medical Oncology, Thomas Jefferson University Hospital, Philadelphia, PA, USA \\ ${ }^{2}$ North Penn Hospital, Landsdale, PA, USA \\ ${ }^{3}$ Division of Orthopedic Oncology, Cooper University Hospital, Camden, NJ, USA \\ Email: ${ }^{*}$ ajw.law150@gmail.com
}

Received 25 August 2014; revised 20 September 2014; accepted 15 October 2014

Copyright (C) 2014 by authors and Scientific Research Publishing Inc.

This work is licensed under the Creative Commons Attribution International License (CC BY). http://creativecommons.org/licenses/by/4.0/

(c) (i) Open Access

\begin{abstract}
Background: As more patients survive cancer chemotherapy, problems associated with the late complications of therapy have become increasingly apparent; late doxorubicin cardio-myopathy being one of the most pressing. The relationship between initial dose, schedule employed, and etiology are still not well defined. This study attempts to clarify some of these issues. Methods: Patients receiving large total doses of doxorubicin by schedules designed to minimize peak drug levels were monitored in regard to their cardiac status for up to 31 years following completion of doxorubicin therapy. A computer program predicting the amount of doxorubicin retained by the heart vs. schedules employed was devised with the predictions of the computer program being compared to the clinical findings. Results: 1365 patients receiving doses of doxorubicin greater than $610 \mathrm{mgm}$./ $\mathrm{M}^{2}$ were monitored for up to 31 years following completion of such therapy. No patient developed unequivocal clinical and pathologic evidence of a doxorubicin related cardiomyopathy. Knowing that human cardio-myocytes contain enzymes capable of neutralizing doxorubicin, a computer program predicted that by increasing their efficiency, the schedules employed substantially 1 decreased the relative amount of drug retained by the heart, findings compatible with both animal experiments and clinical results. Conclusions: administration of doxorubicin by schedules in which peak plasma levels of drug were minimized resulted in marked decreases in both acute and long-term cardiac toxicity; believed to be due to potentiation of myocardial enzymes capable of inactivating the drug.
\end{abstract}

\section{Keywords}

Late Doxorubicin Cardiotoxicity, Initial Type of Doxorubicin Schedule

\footnotetext{
${ }^{*}$ Corresponding author.
}

How to cite this paper: Weiss, A.J., Stoloff, I.L., Simoes, A.C. and Lackman, R.D. (2014) The Relation between the Initial Type of Schedule Used to Administer Doxorubicin and Long-Term Doxorubicin Cardiotoxicity. Journal of Cancer Therapy, 5, 11451152. http://dx.doi.org/10.4236/jct.2014.512117 


\section{Introduction}

Between 1976 in 1996 our group has treated over 6500 patients with doxorubicin, 1365 receiving over 610 mgm./Mㄹ 1014 over 800 mgm./Mㄹ 777 over $900 \mathrm{mgm} . / \mathrm{M}^{2}$, and 448 over $1000 \mathrm{mgm} . / \mathrm{M}^{2}$. Mean dose for the 1014 patient group was $1085 \mathrm{mgm} . / \mathrm{M}^{2}$. All schedules minimized peak plama drug levels.

\section{Schedules}

Once a patient received $500 \mathrm{mgm} . / \mathrm{M}^{2}$ a cardiac workup utilizing all available tools was performed. Any abnormality prevented them from continuing to receive doxorubicin. None so eliminated ever developed evidence of a cardomyopathy. The primary causes of elimination were uncontrolled hypertension or coronary artery insufficiency. Patients receiving radiation therapy to the chest wall were also excluded.

Patients with carcinomas of the breast, ovary, and lymphomas received approximately 65\% of their drug by continuous infusion, the remainder by weekly or twice weekly bolus. All other patients received their drug by bolus, either weekly or twice a week. The continuous infusion dose was between 6 and $8 \mathrm{mgm} . / \mathrm{M}^{2} / \mathrm{day}$, maximum $10 \mathrm{mgm} . /$ day. Infusions continued until the white count nadir was under $2250 / \mu \mathrm{l}$., provided the platelet count was above $25,000 / \mu \mathrm{l}$. Infusions were restarted as soon as the WBC was above $4000 / \mu l$ provided the platelet count was above 80,000/ $\mu \mathrm{l}$. Except for patients with lymphomas, patients were given concomitant G-CSF or GM-CSF. Bolus dose was $20 \mathrm{mgm} . / \mathrm{M}^{2}$; limit $25 \mathrm{mgm}$. Dosage was adjusted so that the WBC nadir was between

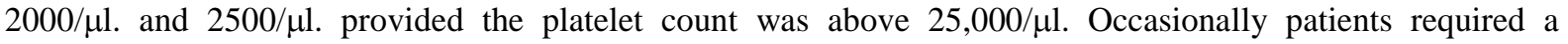
twice-weekly dose. Approximately 50\% of patients received either GM-CSF or G-CSF with Doxorubicin, although many did not receive this with every injection

Since the relationship of the incidence of cardiac failure to total dosage of Doxorubicin was well defined and easy to determine it was decided that this should be the primary parameter measured. Since the incidence of overt cardiac failure appears to be a linear function of dose, the incidence of cardiac failure in the group of 1014 patients who received more than $800 \mathrm{mgm} . / \mathrm{M}^{2}$ by the standard 21 day bolus schedule should be substantially greater than $50 \%$ [1]-[8].

\section{Results}

853 patients died within two years of receiving their last doxorubicin dose, 6 developing evidence of cardiac failure. Two were due to myocardial infarctions as shown by electrocardiography and CPK elevations. One patient's cardiac failure was associated with acute renal failure, subsiding once the renal failure was corrected. An autopsy performed several months later failed to show any evidence of a doxorubicin cardio-myopathy. Another was associated with extensive myocardial metastasis. The fifth patient was a woman with ovarian carcinoma treated with doxorubicin and cyclophosphamide that had a remission lasting two years before relapsing. After several experimental agents failed she received a repeat course of doxorubicin. Several months after completing doxorubicin she developed acute cardiac failure. Her total dose of doxorubicin was $1280 \mathrm{mgm}$./ $\mathrm{M}^{2}$. An autopsy including electron microscopy of her heart revealed essentially normal cardio-myocytes, with practically no mitochondrial or nuclear damage. Left ventricular wall thickness was slightly increased. Minimal extra-cellular edema was noted. These findings were reviewed by several expert pathologists, and a typical statement was "if this was Adriamycin cardiomyopathy it is unlike any pictures that I have ever seen of Adriamycin cardiomyopathy” [6] [8]. The 6th patient developed a typical picture of doxorubicin cardiotoxicity after receiving 914 mgm. $/ \mathrm{M}^{2}$ of drug at our clinic. Further investigation revealed that she had received $425 \mathrm{mgm} . / \mathrm{M}^{2}$ of doxorubicin at a Mexican clinic given by a standard 21-day schedule prior to being treated at our clinic. She withheld this information from us knowing that such information would preclude her from receiving doxorubicin.

Of the remaining 491 patients six have been lost to follow-up. Five left the United States but relatives living in the USA stated that they believed they were still alive and free of cardiac disease. Of the patients who died, 378 were followed at one of our clinics, the remainder moved from the Philadelphia area and information containing the patient status was obtained from various sources, primarily phone or e-mail conversations with surviving family members, or correspondence with referring physicians. Six patients had episodes of dyspnea. All were believed to have a viral infection. None of their chest X-rays showed evidence of cardiac enlargement and with all, symptoms disappeared as the viral infection abated. Seven had dyspnea associated with COPD. All were moderate to heavy smokers and 4 had symptoms of COPD prior to receiving doxorubicin. Cardiologists 
evaluated all and none were believed to have intrinsic doxorubicin related myocardial disease, although 3 had evidence of coronary arterial disease. Four developed symptoms of coronary artery disease with limitations in their exercise tolerance, however none had any evidence of a cardiomyopathy. One developed cardiac failure associated with an episode of uncontrolled supra-ventricular tachycardia, his symptoms of cardiac failure disappeared once his heart rate came under control and the cardiologist evaluating him stated that there was no evidence of intrinsic ventricular myocardial disease although he did have evidence of coronary arterial disease. Three patients, all over 50 years in age, had well controlled atrial fibrillation without evidence of cardiac failure.

The diagnoses of the 41 patients known to be alive as of 2010 were as follows Lymphomas 11, carcinoma of the lung 1, esophagus1, breast 17, ovary 2, testicle 2, unknown primary 1, and soft tissue and osteosarcomas 6. Their ages at the time therapy was started ranged from 12 to 42 . Twenty-nine were female, 12, male. Total doxorubicin doses ranged from $612 \mathrm{mgm} . / \mathrm{M}^{2}$ to $1652 \mathrm{mgm} . / \mathrm{M}^{2}$.

Mean dose in women, $978 \mathrm{mgm} . / \mathrm{M}^{2}$, men, $1253 \mathrm{mgm} . / \mathrm{M}^{2}$.

These are minimal doses, possibly some patients received doses of doxorubicin that missed being recorded.

Cardiologists evaluated seven patients. Five had ejection fractions greater than $50 \%$ and were told that there was no evidence of cardiovascular disease. The other two only were told that there was no evidence of cardiovascular disease. Two hypertensive patients were told they had no evidence of intrinsic doxorubicin related cardiovascular disease although both were told that there was evidence of old myocardial infarctions. Another was told that he had a partial left bundle branch block, another that he had a moderately elevated diastolic B.P. and a prolonged Q-T interval, but no evidence of a cardio-myopathy. One patient admitted to episodes of dyspnea, she was known to be an asthmatic and was told that her heart, while slightly enlarged, was otherwise normal. Another admitted to tiring easily but had severe osteoarthritis and was told that her heart was basically normal for her age. Thus, in this whole group of 1365 patients, only two developed a clinical picture compatible with cardiac failure due to a doxorubicin cardio-myopathy, one was not confirmed by post mortem studies, the other known to have received a large dose of an antracycline by a standard regime prior to receiving doxorubicin at our clinic

We believe that the detailed cardiac evaluation of this group of patients would be of little value. The only cardiac evaluation available at the time that most of these patients started therapy was a chest X-ray, electrocardiogram, and CPK. Almost all received other anti-cancer agents, either with or independent of doxorubicin. Many received several hormonal agents. Long intervals had occurred since completing therapy, changes in cardiac function due to aging, inter-current diseases and their associated therapies, alcohol and tobacco exposure, etc. would interfere with such an evaluation. The salient fact remains that for a protracted period following the administration of large doses of doxorubicin this group failed to show any increase in clinically evident heart disease, and the common denominator was the selection of schedules that minimized peak plasma doxorubicin levels.

\section{Discussion}

Shortly after doxorubicin was introduced, it was noted that cardiomyopathy occurred in a significant percentage of individuals receiving more than $550 \mathrm{mgm} . / \mathrm{M}^{2}$, and that two modifications of scheduling, one in which an equivalent amount of drug was given weekly instead of once every 21 days, and another in which the drug is given by continuous infusion, permitted the administration of higher total doses [3] [4] [8]. It was also found that cells resistant to doxorubicin possess active enzymatic complexes able to neutralize the toxicity of doxorubicin, either by extruding the drug from the cell, or by inactivating the compound [9]-[11]. Since the efficiency of essentially all enzymatic processes decreases as the concentration of the substrate increases [12], it was suggested that cardio-myocytes possess such enzymes, their efficiency decreasing when high levels of doxorubicin were present [13] [14]. Such enzymes are found to be present in human cardiac myocytes and their characteristics determined [15]-[19]. By computer, we tested the hypothesis that the protective effect of schedule modification was due to the fact that such modifications increased the efficiency of this enzymatic process, thereby reducing the amount of doxorubicin retained by the heart, assuming that

1) Doxorubicin enters cardio-myocytes, sensitive neoplastic cells, and pertinent hematopoietic elements by diffusion, thus the amount of drug entering the cell approximates a linear function of dose. This has been demonstrated to be true for a variety of cell types [9] [10].

2) Enzymatic process exists in the human cardio-myocyte capable of inactivating the drug [15]-[19]. 
3) While the kinetics the reaction described are probably more complex than that is used here, it is believed that the Michaelis-Menten equation serves as an adequate model

4) The major doxorubicin plasma half-life constant is 17 hours. Varying the half-life reveals that the differential increases as the half-life decreases and decreases but does not disappear with increases in the half-life. Increasing the half-life to 36 hours resulted in less than $10 \%$ change in relative but not absolute results

5) The Michaelis-Menten equation constants were arbitrary, however the program has been run varying large number of constants and while absolute values change, within limits, the relationship of the values does not. The program has been modified assuming doxorubicin enters cells by active transport, without significant change in the relationship of doxorubicin uptake in cardiac myocytes to uptake in hematopoietic elements.

6) Since hematopoietic toxicity and response of sensitive tumors are independent of scheduling and are believed to be devoid of such enzymatic processes their drug uptake will be schedule independent.

Program Chipmunk Basic 600 sluices/Minute [20].

The simplest explanation of our clinical findings is that these schedule modifications decrease the amount of doxorubicin accumulated by the heart. Pacciarini's group demonstrated that mice receiving divided doses of doxorubicin had the same amount of drug in tumor and spleen but much lower amounts in their hearts than mice receiving an equivalent single dose [21]. The computer-generated data demonstrates that schedule modification is capable of accomplishing this. Thus, infusion doses totaling $2000 \mathrm{mgm} . / \mathrm{M}^{2}$, result in less cardiac accumulation of doxorubicin than a dose of 550/mgm./ $/ \mathrm{M}^{2}$, given by high-dose bolus. The efficiency of dividing the single injection of Doxorubicin into weekly injections is born out by the data shown in table one. Clinically in has been found that short infusions are not associated with protection of the heart, while infusions carried out over longer periods are [22] [23] findings presented in Table 1 predict this.

Patients treated with low doses of doxorubicin can develop evidence of a cardio-myopathy many years later. Many did not shown evidence of cardio-myopathy initially [24]-[28]. The lack of late clinically evident doxorubicin cardio-toxicity in our group suggests the techniques protecting against early doxorubicin cardio-toxicity are protective against late cardio-toxicity.

Our protocols may protect the ovary, since our regimes did not appear to affect the fertility of women so treated [29].

It has been found that with other non-anthracycline therapeutic regimes, changing from long interval bolus regime to a weekly regime is better tolerated and more effective [30]. A similar mechanism of protection may apply.

This suggests the following. If a specific organ toxicity is dose limiting and is found to be dependent upon scheduling, with those schedules permitting high peak levels of drug being more toxic than those that minimizes the peak level of drug, then an optimal course would be one that minimizes these. Organs in which toxicity is independent of scheduling probably lack enzymatic processes that can neutralize that drug.

If cancer cells have an enzymatic neutralizing process for a specific drug, then high dose bolus schedules should be considered. However, the likelihood of that tumor responding to the drug is probably minimal. This appears to be true with doxorubicin since the anti-tumor response rate to doxorubicin appears to be independent of scheduling [3] [4] [23] [31].

Table 1. Cardiac uptake doxorubicin vs various schedules.

\begin{tabular}{|c|c|c|c|c|c|}
\hline & $\begin{array}{c}\text { \% Exposed dose } \\
\text { dox excluded from } \\
\text { heart }\end{array}$ & $\begin{array}{l}\text { Units doxorubicin } \\
\text { retained by } \\
\text { Heart }^{*}\end{array}$ & $\begin{array}{c}\text { Equivalent dose } \\
\text { dox for cardiac } \\
\text { toxicity } \\
\text { mgm./M } \mathrm{M}^{2 \#}\end{array}$ & $\begin{array}{l}\text { Heart exposure to dox } 10 \\
\text { U above Km }\end{array}$ & $\begin{array}{c}\text { Maximum } \\
\text { plasma } \\
\text { level in } U\end{array}$ \\
\hline 1 Bolus q 21 days & $30.40 \%$ & 550 & 550 & 3.14 & 79.39 \\
\hline 3 Bolus injections q 21 days & $70.32 \%$ & 226.6 & 1290 & 3.02 & 25.07 \\
\hline 9 Bolus injections q 21 days & $79.65 \%$ & 152.63 & 1881 & 0 & 9.73 \\
\hline 21 Bolus injections in 21 days q 21 days & $79.88 \%$ & 150.9 & 1903 & 0 & 6.32 \\
\hline 4 Day infusion q 21 days & $38.16 \%$ & 483.62 & 619 & 2.83 & 21.73 \\
\hline 11 Day infusion q 21 days & $54.91 \%$ & 338.82 & 849 & 0 & 8.2 \\
\hline 21 Day infusion q 21 days & $81.39 \%$ & 139.92 & 2057 & 0 & 4.29 \\
\hline
\end{tabular}

$\mathrm{V}_{\max }=1.00(\mu \mathrm{g} / \mathrm{ml}) / \mathrm{sec} ; \mathrm{Km}=0.1 \mu \mathrm{g} / \mathrm{ml}$, Michaelis Menten eq $\mathrm{dS} / \mathrm{dt}=\mathrm{V}_{\max } \times \mathrm{S} /(\mathrm{Km}+\mathrm{S}) ; \mathrm{S}=$ Doxorubicin Extra-cellular Concentration; ${ }^{*}$ Relative

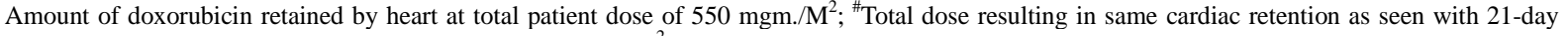
bolus protocol. Total dose dox in 21-day period = $75 \mathrm{mgm} . / \mathrm{M}^{2}$. Doxorubicin $1 / 2$ life 17 hours: $\mathrm{S}=$ substrate concentration. Hematopoetic tissue and sensitive tumor uptake unaffected by scheduling $\left[\mathrm{V}_{\max }=0\right]$. 
It is known that cancer cells can develop such pathways [9] [10]. Theoretically, it may be worth considering courses in which continuous low dose infusions or its equivalent are alternated with high-dose bolus injections in an attempt to prevent this from happening.

Our studies suggest that the initial cardiac protection resulting from regimes that suppress high peak plasma levels of doxorubicin, also protect against late cardiac dysfunction. Since adult cardiac myocytes do not divide, and there is no evidence of acute death of cardiac myocytes when late doxorubicin induced cardiac failure occurs [25]-[28], it is probable that until methods are devised to replace cardio-myocytes, the primary method of preventing late doxorubicin cardiac toxicity is by optimizing methods to protect the heart during initial exposure to the drug

The presence of enzymatic processes capable of protecting the heart against various toxic agents is wellestablished [11] [19] [32]-[37] and the clinical data is compatible with the hypothesis that the type of schedule used can adversely affect this process. Many agents, such as the calcium channel blocking agents, and others designed to neutralize the MDR complex responsible for drug resistance, could interfere with this process [34]-[37]. Defining the influence of such agents upon the various enzymatic processes in the myocardium should be carried out before these agents are introduced into clinical practice.

The following question results: are the properties of the protective complexes in the human heart similar to MDR complexes, and do its properties vary in different patients, thus explaining the patient variability in the development of doxorubicin induced cardiac toxicity?

Many groups use schedules that suppress peak plasma levels of doxorubicin, such as protocols utilizing doxil, a slowly releasing complex of doxorubicin with a liposome. Such studies suggest that a reduction in early cardiac toxicity and possibly late cardiac toxicity may be achieved in this manner [38] [39]. This questions the continued standard use of the three-week bolus schedule of doxorubicin.

If MDR like enzymes play a role in protecting an organ from various toxins, could assaying their level in that organ or related organs allow one to predict which patients will be damaged when exposed to these agents? Would it be possible to selectively enhanced the activity of these enzymes and thus protect the organ? The finding that vincristine interferes with doxorubicin uptake by cardio-myocytes suggests that this is possible [6].

Many of our patients received either G-CSF or GM-CSF with their doxorubicin. Recently, it has been postulated that this may be cardio-protective [40] [41]. Whether this is a factor in our clinical findings is not known, however approximately $50 \%$ of the group did not receive either agent.

In 1977 we postulated that doxorubicin cardiac toxicity was related to peak plasma levels of drug as well as total dose of drug received by the patient [3]. While this appears to be true we believe that this finding is indirect, reflecting the fact that regimes that allow high peak levels of drug are those regimes that interfere with the activity of enzymes in the cardio-myocyte able to inactivate doxorubicin. In our opinion, the most important factor in the causation of cardiac toxicity is the total amount of doxorubicin accumulated by the heart, not peak plasma drug levels.

\section{Conclusions}

1365 patients receiving between $610 \mathrm{mgm} . / \mathrm{M}^{2}$ and $1652 \mathrm{mgm} . / \mathrm{M}^{2}$ of doxorubicin (mean dose 1085 mgm./Mㄹ) more than 30 years ago by schedules designed to minimize peak plasma levels of drug were surveyed. Despite an expected incidence of overt cardiac failure believed to be over 50\%, only 2 patients developed episodes of congestive heart failure possibly due to doxorubicin. One received large doses of an anthracycline by a standard protocol prior to starting our regime, the other despite having a classic clinical picture of a doxorubicin induced cardiomyopathy, had no evidence of such by electron microscopy. A computer program was developed in which it was postulated that human cardiac myocytes possessed enzymatic complexes capable of inactivating doxorubicin while sensitive neoplastic cells and pertinent hematopoietic elements lacked these. The program demonstrated that low peak level schedules decreased the amount of doxorubicin accumulated by the heart without changing the amount accumulated by neoplastic tissue and blood forming elements. Studies of patients receiving high total doses of doxorubicin by other protocols in which peak drug levels were minimized demonstrated that similar changes in scheduling resulted in a decrease in acute cardiac morbidity without adversely affecting anti-tumor responses. This supports the hypothesis that the favorable effects are due, at least in part, to a decrease in the amount of doxorubicin retained by the heart. It raises the possibility that specific agents could interfere 
with this process thus increasing the cardio-toxicity of doxorubicin. It is also possible that agents exist that increases the activity of these units, thus protecting the heart against doxorubicin cardiac toxicity.

At present, computer programming has not been a major factor in planning clinical trial schedules. Our experience suggests utilizing the pharmacologic characteristics of both tumor and dose limiting normal tissues, computer programs can be aid in optimizing such schedules.

\section{References}

[1] Adão, R., de Keulenaer, G., Leite-Moreira, A. and Brás-Silva, C. (2013) Cardiotoxicity Associated with Cancer Therapy: Pathophysiology and Prevention Strategies. Revista Portuguesa de Cardiologia, 32, 395-409. http://dx.doi.org/10.1016/j.repc.2012.11.002

[2] Lefrak, E.A., Pitha, J., Rosenheim, S. and Gottlieb, J.A. (1973) A Clinicopathologic Analysis of Adriamycin Cardiotoxicity. Cancer, 32, 302-314. http://dx.doi.org/10.1002/1097-0142(197308)32:2<302::AID-CNCR2820320205>3.0.CO;2-2

[3] Weiss, A.J. and Manthel, R.W. (1977) Experience with the Use of Adriamycin in Combination with Other Anticancer Agents Using a Weekly Schedule, with Particular Reference to Lack of Cardiac Toxicity. Cancer, 40, $2046-2052$. http://dx.doi.org/10.1002/1097-0142(197711)40:5<2046::AID-CNCR2820400508>3.0.CO;2-5

[4] Von Hoff, D.D., Layard, M.W., Basa, P., Davis Jr., H.L., Von Hoff, A.L., Rozencweig, M. and Muggia, F.M. (1979) Risk Factors for Doxorubicin-Induced Congestive Heart Failure. Annals of Internal Medicine, 91, 710-717. http://dx.doi.org/10.7326/0003-4819-91-5-710

[5] Swain, S.M., Whaley, F.S. and Ewer, M.S. (2003) Congestive Heart Failure in Patients Treated with Doxorubicin: A Retrospective Analysis of Three Trials. Cancer, 97, 2869-2879. http://dx.doi.org/10.1002/cncr.11407

[6] Zhang, J.Q., Honbo, N. and Karlinger, J.S. (2010) Doxorubicin Cardiomyopathy. Cardiology, 115, 155-162 http://dx.doi.org/10.1159/000265166

[7] Elbl, L., Hrstkova, H., Chaloupka, V., Novotny, J. and Michalek, J. (2003) The Evaluation of Left Ventricular Function in Childhood Cancer Survivors by Pharmacological Stress Echocardiography. Neoplasma, 50, 191-197.

[8] Torti, F.M., Bristow, M.R., Howes, A.E., Aston, D., Stockdale, F.E., Carter, S.K., Kohler, M., Brown Jr., B.W. and Billingham, M.E. (1983) Reduced Cardiotoxicity of Doxorubicin Delivered on a Weekly Schedule. Assessment by Endomyocardial Biopsy. Annals of Internal Medicine, 99, 745-749. http://dx.doi.org/10.7326/0003-4819-99-6-745

[9] Mads, D. and Else, K. (1983) Hoffmann Doxorubicin (Adriamycin) Transport in Ehrlich ascites Tumour Cells: Comparison with Transport in Human Red Blood Cells. Scandinavian Journal of Laboratory and Clinical Medicine, 43, 241-248.

[10] Kerr, D.J., Kerr, I.M., Freshney, R.I. and Kaye, S.B. (1986) Comparative Intracellular Uptake of Adriamycin and 4'-Deoxydoxorubicin by Nonsmall Cell Lung Tumor Cells in Culture and Its Relationship to Cell Survival. Biochemical Pharmacology, 35, 2817-282. http://dx.doi.org/10.1016/0006-2952(86)90195-4

[11] Hu, M., Liu, Y.P., Deng, C.H., Han, R.F., Jia, Y.H., Liu, S.W., Jiang, Z.M., Cao, X.C., He, L. and Zhang, Q.P. (2011) Enhanced Invasiveness in Multidrug Resistant Leukemic Cells Is Associated with Overexpression of P-Glycoprotein and Cellular Inhibitor of Apoptosis Protein. Leukemia \& Lymphoma, 52, 1302-1311. http://dx.doi.org/10.3109/10428194.2011.572323

[12] Seibert, E. and Tracy, T.S. (2014) Different Enzyme Kinetic Models. Methods in Molecular Biology, 1113, $23-35$. http://dx.doi.org/10.1007/978-1-62703-758-7 33

[13] Weiss, A.J., Barrueco, C.J., Kocsis, J.J. and Bianchi, C.P. (1984) Doxorubicin Efflux from Isolated Rat Hearts at 37\% and 25\% C. Federation of American Societies for Experimental Biology (Pharmacology), 5, 53.

[14] Weiss, A.J., Barrueco, C.J., Kocsis, J.J. and Bianchi, C.P. (1985) Doxorubicin Transport Using an Improved Preparation of Calcium Proc Resistant Cardiac Myocytes from Adult Rats. American Society for Pharmacology and Experimental Therapeutics, 234, 166.

[15] McCaffrey, T.A., Tziros, C., Lewis, J., Katz, R., Siegel, R., Weglicki, W., Kramer, J., Mak, I.T., Toma, I., Chen, L., Benas, E., Lowitt, A., Rao, S., Witkin, L., Lian, Y., Lai, Y., Yang, Z. and Fu, S.W. (2013) Genomic Profiling Reveals the Potential Role of TCL1A and MDR1 Deficiency in Chemotherapy-Induced Cardiotoxicity. International Journal of Biological Sciences, 9, 350-360. http://dx.doi.org/10.7150/ijbs.6058

[16] Maurício, K.S., Lino, O.P., Elza, S.M., Damiana, V.R., Juliane, R.S., Bibiana, A.S. and Mariana, R.F. (2006) MRPI/ GS-X Pump ATPase Expression Is This the Explanation for the Cytoprotection of the Heart against Oxidative StressInduced Redox Imbalance in Comparison to Skeletal Muscle Cells? Cell Biochemistry and Function, 25, $23-32$.

[17] Hasinoff, B.B., Patel, D. and Wu, X. (2013) The Dual-Targeted HER1/HER2 Tyrosine Kinase Inhibitor Lapatinib Strongly Potentiates the Cardiac Myocyte-Damaging Effects of Doxorubicin. Cardiovascular Toxicology, 13, 33-47. 
http://dx.doi.org/10.1007/s12012-012-9183-x

[18] Couture, L., Nash, J.A. and Turgeon, J. (2006) The ATP-Binding Cassette Transporters and Their Implication in Drug Disposition: A Special Look at the Heart. Pharmacological Reviews, 58, 244-258. http://dx.doi.org/10.1124/pr.58.2.7

[19] Wang, J., Nachtigal, M.W., Kardami, E. and Cattini, P.A. (2013) FGF-2 Protects Cardiomyocytes from Doxorubicin Damage via Protein Kinase C-Dependent Effects on Efflux Transporters. Cardiovascular Research, 98, 56-63. http://dx.doi.org/10.1093/cvr/cvt011

[20] Valko, P. and Vajda, S. (1989) Advanced Scientific Computing in Basic with Applications in Chemistry, Biology and Pharmacology (Data Handling in Science and Technology). Elsevier, Amsterdam, 268.

[21] Pacciarini, M.A., Barbieri, B., Colombo, T., Broggini, M., Garattini, S. and Donelli, M.G. (1978) Distribution and Antitumor Activity of Adriamycin Given in a High Dose and a Repeated Low-Dose Schedule to Mice. Cancer Treatment Reports, 62, 791-800.

[22] Lipshultz, S.E., Giantris, A.L., Lipsitz, S.R., Kimball Dalton, V., Asselin, B.L., Barr, R.D., Clavell, L.A., Hurwitz, C.A., Moghrabi, A., Samson, Y., Schorin, M.A., Gelber, R.D., Sallan, S.E. and Colan, S.D. (2002) Doxorubicin Administration by Continuous Infusion Is Not Cardioprotective: The Dana-Farber 91-01 Acute Lymphoblastic Leukemia Protocol. Journal of Clinical Oncology, 20, 1677-1682. http://dx.doi.org/10.1200/JCO.20.6.1677

[23] Berrak, S.G., Ewer, M.S., Jaffe, N., Pearson, P., Ried, H., Zietz, H.A. and Benjamin, R.S. (2001) Doxorubicin Cardiotoxicity in Children: Reduced Incidence of Cardiac Dysfunction Associated with Continuous-Infusion Schedules. Oncology Reports, 8, 611-614.

[24] Drafts, B.C., Twomley, K.M., D’Agostino Jr., R., Lawrence, J., Avis, N., Ellis, L.R., Thohan, V., Jordan, J., Melin, S.A., Torti, F.M., Little, W.C., Hamilton, C.A. and Hundley, W.G. (2013) Low to Moderate Dose Anthracycline-Based Chemotherapy Is Associated with Early Noninvasive Imaging Evidence of Subclinical Cardiovascular Disease. JACC: Cardiovascular Imaging, 6, 877-885. http://dx.doi.org/10.1016/j.jcmg.2012.11.017

[25] Lipshultz, S.E., Lipsitz, S.R., Sallan, S.E., Dalton, V.M., Mone, S.M., Gelber, R.D. and Colan, S.D. (2005) Chronic Progressive Cardiac Dysfunction Year after Doxorubicin Therapy for Childhood Acute Lymphoblastic Leukemia. Journal of Clinical Oncology, 23, 2629-2636. http://dx.doi.org/10.1200/JCO.2005.12.121

[26] Ali, M.K., Ewer, M.S., Gibbs, H.R., Swafford, J. and Graff, K.L. (1994) Late Doxorubicin-Associated Cardiotoxicity in Children. The Possible Role of Intercurrent Viral Infection. Cancer, 74, 182-188. http://dx.doi.org/10.1002/1097-0142(19940701)74:1<182::AID-CNCR2820740129>3.0.CO;2-2

[27] Steinherz, L.J., Steinherz, P.G., Tan, C.T., Heller, G. and Murphy, M.L. (1991) Cardiac Toxicity 4 to 20 Years after Completing Anthracycline Therapy. JAMA, 266, 1672-1677. http://dx.doi.org/10.1001/jama.1991.03470120074036

[28] Healey, B.R.J. and Swain, S.M. (2008) Cardiac Toxicity in Breast Cancer Survivors: Review of Potential Cardiac Problems. Clinical Cancer Research, 1, 14-24.

[29] Hosalkar, H.S., Henderson, K.M., Weiss, A., Donthineni, R. and Lackman, R.D. (2004) Chemotherapy for Bone Sarcoma Does Not Affect Fertility Rates or Childbirth. Clinical Orthopaedics and Related Research, 428, 256-260. Erratum in: Clinical Orthopaedics, 429, 352. http://dx.doi.org/10.1097/01.blo.0000137547.14953.1e

[30] Ramalingam, S., Perry, M.C., La Rocca, R.V., Rinaldi, D., Gable, P.S., Tester, W.J. and Belani, C.P. (2008) Comparison of Outcomes for Elderly Patients Treated with Weekly Paclitaxel in Combination with Carboplatin versus the Standard 3-Weekly Paclitaxel and Carboplatin for Advanced Nonsmall Cell Lung Cancer. Cancer, 113, 542-546. http://dx.doi.org/10.1002/cncr.23583

[31] Weiss, A.J. (1984) Studies on Cardiotoxicity and Antitumor Effect of Doxorubicin Administered Weekly. Cancer Treatment Symposia, 3, 91-94.

[32] de Nigris, F., Rienzo, M., Schiano, C., Fiorito, C., Casamassimi, A. and Napoli, C. (2008) Prominent Cardioprotective Effects of Third Generation Beta Blocker Nebivolol against Anthracycline-Induced Cardiotoxicity Using the Model of Isolated Perfused Rat Heart. European Journal of Cancer, 44, 334-340. http://dx.doi.org/10.1016/j.ejca.2007.12.010

[33] Huh, W.W., Jaffe, N., Durand, J.B., Munsell, M.F. and Herzog, C.E. (2010) Comparison of Doxorubicin Cardiotoxicity in Pediatric Sarcoma Patients When Given with Dexrazoxane versus as Continuous Infusion. Pediatric HematologyOncology, 27, 546-557. http://dx.doi.org/10.3109/08880018.2010.503335

[34] Tsubaki, M., Komai, M., Itoh, T., Imano, M., Sakamoto, K., Shimaoka, H., Takeda, T., Ogawa, N., Mashimo, K., Fujiwara, D., Mukai, J., Sakaguchi, K., Satou, T. and Nishida, S. (2014) By Inhibiting Src, Verapamil and Dasatinib Overcome Multidrug Resistance via Increased Expression of Bim and Decreased Expressions of MDR1 and Survivin in Human Multidrug-Resistant Myeloma Cells. Leukemia Research, 38, 121-130. http://dx.doi.org/10.1016/j.leukres.2013.10.017

[35] Mould, E., Berry, P., Jamieson, D., Hill, C., Cano, C., Tan, N., Elliott, S., Durkacz, B., Newell, D. and Willmore, E. (2014) Identification of Dual DNA-PK MDR1 Inhibitors for the Potentiation of Cytotoxic Drug Activity. Biochemical Pharmacology, 88, 58-65. http://dx.doi.org/10.1016/j.bcp.2014.01.001 
[36] Li, J., Xu, L.Z., He, K.L., Guo, W.J., Zheng, Y.H., Xia, P. and Chen, Y. (2001) Reversal Effects of Nomegestrol Acetate on Multidrug Resistance in Adriamycin-Resistant MCF7 Breast Cancer Cell Line. Breast Cancer Research, 3, 253-263. http://dx.doi.org/10.1186/bcr303

[37] Juvale, K., Stefan, K., Juvale, K., Stefan, K. and Wiese, M. (2013) Synthesis and Biological Evaluation of Flavones and Benzoflavones as Inhibitors of BCRP/ABCG2. European Journal of Medicinal Chemistry, 67, 115-126. http://dx.doi.org/10.1016/j.ejmech.2013.06.035

[38] Safra, T., Muggia, F., Jeffers, S., Tsao-Wei, D.D., Groshen, S., Lyass, O., Henderson, R., Berry, G. and Gabizon, A. (2000) Pegylated Liposomal Doxorubicin (doxil): Reduced Clinical Cardiotoxicity in Patients Reaching or Exceeding Cumulative Doses of 500 mg/m². Annals of Oncology, 11, 1029-1033. http://dx.doi.org/10.1023/A:1008365716693

[39] Rafiyath, S.M., Rasul, M., Lee, B., Wei, G., Lamba, G. and Liu, D. (2012) Comparison of Safety and Toxicity of Liposomal Doxorubicin vs. Conventional Anthracyclines: A Meta-Analysis. Experimental Hematology \& Oncology, 1, 10. http://dx.doi.org/10.1186/2162-3619-1-10

[40] Tomita, S., Ishida, M., Nakatani, T., Fukuhara, S., Hisashi, Y., Ohtsu, Y., Suga, M., Yutani, C., Yagihara, T., Yamada, K. and Kitamura, S. (2004) Bone Marrow Is a Source of Regenerated Cardiomyocytes in Doxorubicin-Induced Cardiomyopathy and Granulocyte Colony-Stimulating Factor Enhances Migration of Bone Marrow Cells and Attenuates Cardiotoxicity of Doxorubicin under Electron Microscopy. Journal of Heart and Lung Transplantation, 23, 577-584. http://dx.doi.org/10.1016/j.healun.2003.06.001

[41] Li, L., Takemura, G., Li, Y., Miyata, S., Esaki, M., Okada, H., Kanamori, H., Ogino, A., Maruyama, R., Nakagawa, M., Minatoguchi, S., Fujiwara, T. and Fujiwara, H. (2007) Granulocyte Colony-Stimulating Factor Improves Left Ventricular Function of Doxorubicin-Induced Cardiomyopathy. Laboratory Investigation, 87, 440-455. 
Scientific Research Publishing (SCIRP) is one of the largest Open Access journal publishers. It is currently publishing more than 200 open access, online, peer-reviewed journals covering a wide range of academic disciplines. SCIRP serves the worldwide academic communities and contributes to the progress and application of science with its publication.

Other selected journals from SCIRP are listed as below. Submit your manuscript to us via either submit@scirp.org or Online Submission Portal.
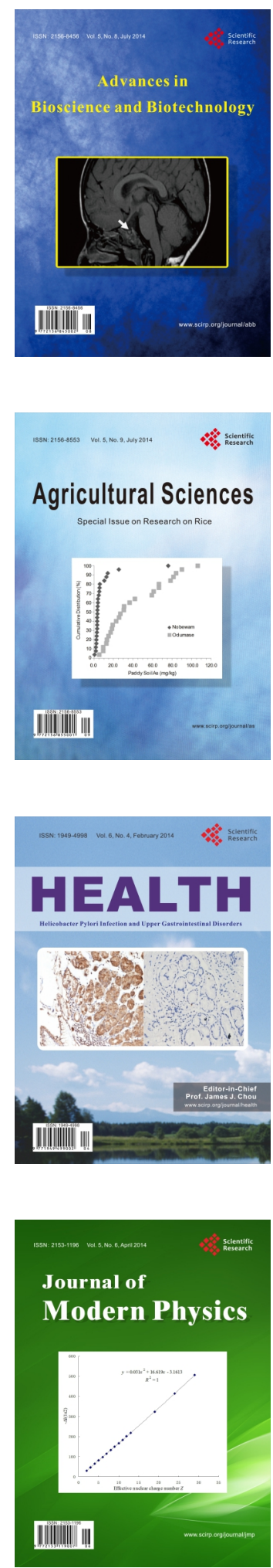
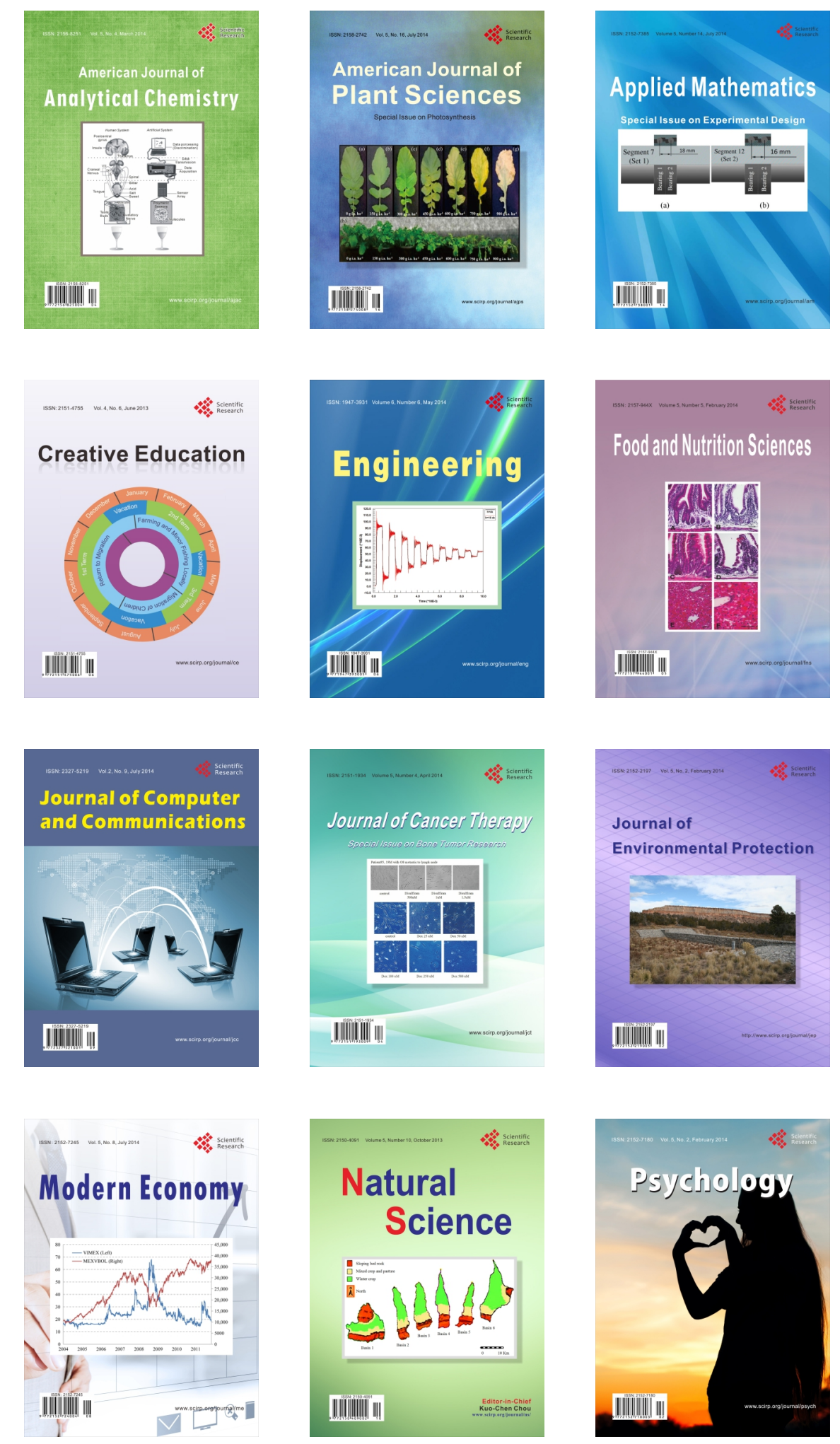